\title{
Site Selection Models in Natural Disaster Shelters:
} A Review

\author{
Yunjia Ma ${ }^{1,2,3}$, Wei Xu ${ }^{1,2,3, *}$, Lianjie Qin ${ }^{1,2,3}$ and Xiujuan Zhao ${ }^{4, *}$ \\ 1 Key Laboratory of Environmental Change and Natural Disaster of Ministry of Education, \\ Faculty of Geographical Science, Beijing Normal University, Beijing 100875, China; \\ mayj@mail.bnu.edu.cn (Y.M.); qinlianjie@mail.bnu.edu.cn (L.Q.) \\ 2 State Key Laboratory of Earth Surface Processes and Resource Ecology, Beijing Normal University, \\ Beijing 100875, China \\ 3 Academy of Disaster Reduction and Emergency Management, Ministry of Emergency Management and \\ Ministry of Education, Beijing Normal University, Beijing 100875, China \\ 4 Department of Engineering Physics, Tsinghua University, Beijing 100084, China \\ * Correspondence: xuwei@bnu.edu.cn (W.X.); xjzhao@mail.tsinghua.edu.cn (X.Z.)
}

Received: 8 November 2018; Accepted: 8 January 2019; Published: 14 January 2019

check for updates

\begin{abstract}
Constructing natural disaster shelters is important for disaster emergency management, and site selection models provide a feasible technique and method. This paper presents site selection models for natural disaster shelters. A synthesis of the types, objectives, constraints, methods of solutions, targeted disasters and applications of different site selection models for natural disaster shelters is investigated. Shelter location models can be classified as single-objective models, multiobjective models and hierarchical models, according to the objective and hierarchy type. Minimizing the evacuation distance or time, shelter construction cost or number, and the total risk are the general objectives of the models. Intelligent optimization algorithms are widely used to solve the models, instead of the Geographic Information System (GIS) method, due to the complexity of the problem. The results indicate that the following should be the main focuses of future works: How to set a model that can be applied for determining the shelter locations of multiple disasters; how to consider the uncertainty in the models; how to improve the existing algorithms or models to solve large-scale location-allocation problems; and how to develop a new resource-saving model that is consistent with the concept of sustainable development, as advocated by shelter planners and policy makers, which can be applied in real situations. This study allows those undertaking shelter location research to situate their work within the context of shelter planning.
\end{abstract}

Keywords: natural disaster; shelters; site selection problem; optimization model

\section{Introduction}

Site selection is always an interestingly new problem, although it was proposed in 1909 by Weber [1], who focused on the selection of a warehouse that is nearest to all customers. It is vital to social development and is involved in many fields, such as economics, mathematics, politics, natural science, and so on. At the beginning, the study concerning site selection is not systematic, but is mainly about solving the problems associated with living and produce, and most of them are continuous problems, such as selecting a position for a facility location in a continuous space. Hotelling [2] studied another situation, that of determining the positions of two competitive corporations in a line. Based on this, Smithies [3] and Stevens [4] studied the problem more deeply by considering elastic demands in relation to competitors, who are free to move but are spatially separated. As the practical issues become more complex, how to select the locations from the candidate positions for many facilities at 
the same time has attracted researchers' interest. Under this situation, the models to solve continuous problems are no longer suitable. As a result, in 1964, Hakimi [5] proposed the $p$-median and $p$-center methods to solve the discrete multi-facility site selection problems in a network, which means that the research concerning site selection is becoming systematic. Nowadays, site selection has been applied in various fields, including the site selection of facilities, factories, warehouses, logistics centres and so on. Additionally, based on these basic single-objective models, multiobjective models and hierarchical models have also been proposed, according to the objective or hierarchy types. We note that our study invokes the term "hierarchy" in a broader manner, differing slightly from its use in previous literature concerning location-allocation theory. Namely, different types of facilities and different decision makers can form various hierarchies. The classification of the models used to solve the site selection problem is shown in Table 1.

Table 1. Classification of site selection models.

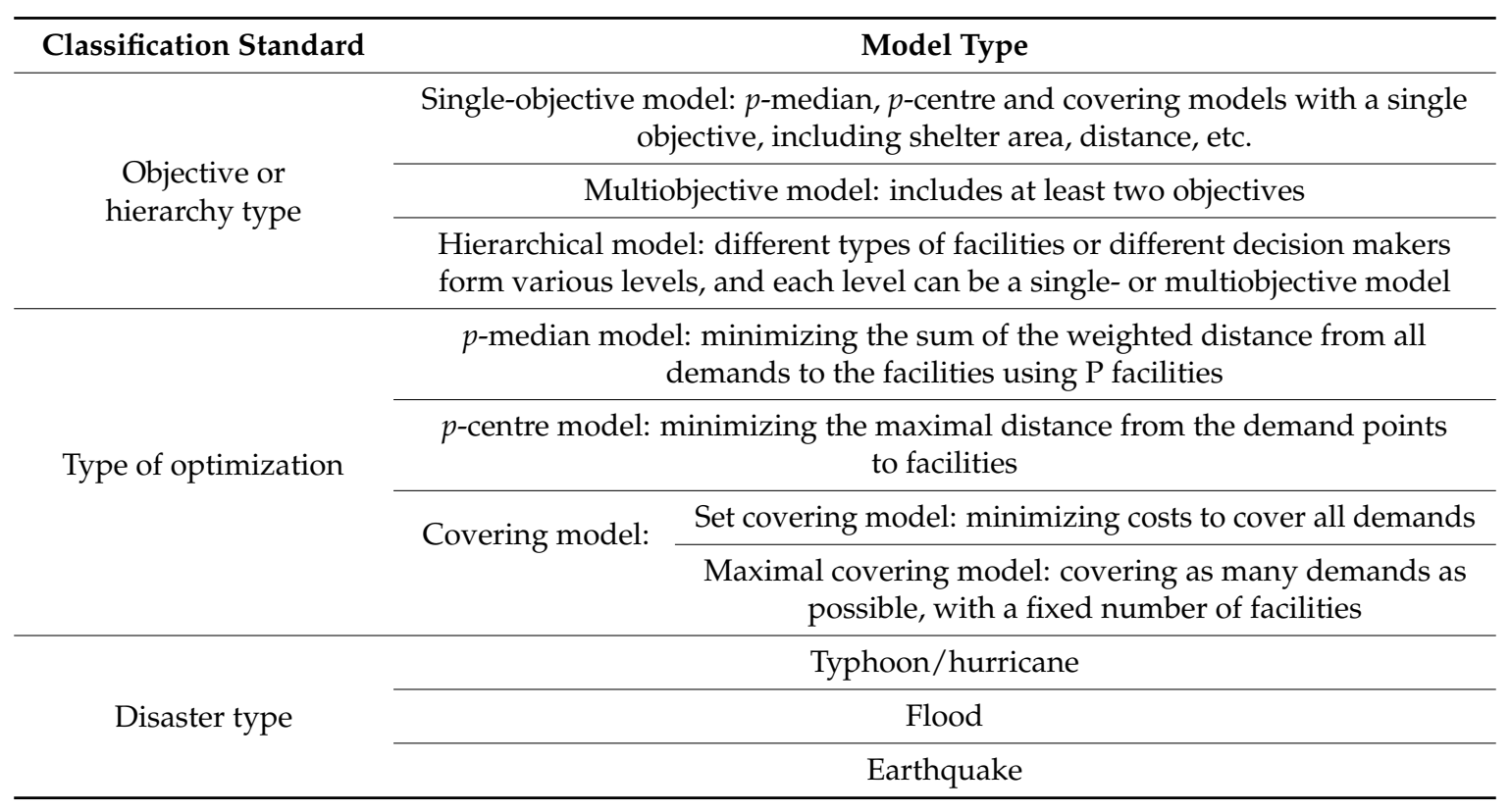

Along with the development of the economy and society, emergency events, which include natural disasters and human-made explosion events, traffic accidents, and terrorists that cause significant disruption and devastation to whole societies, have been in the spotlight [6]. These emergency events, especially natural disasters, have the characteristics of unpredictability, suddenness, catastrophic and timeliness $[7,8]$. In most cases, removing people from the affected area is in the best interest of their health and safety and exposes them to minimal risk [9], thus enhancing urban resilience [10]. A disaster emergency shelter is a safe place for people to live temporarily, when they cannot stay in their previous residence due to an emergency event, such as an earthquake. Therefore, deciding the mode of evacuation is one of the most important questions facing local emergency managers as they respond to natural disasters, such as how to quickly evacuate people, how to assign the affected people to shelters, and how to help affected people go to the hospital quickly. To solve these problems, a site selection model for natural disaster shelters can be modified and used to provide assistance to government decision makers.

Despite the many published applications of site selection, a lack of a literature review that summarizes and discusses natural disaster shelter site selection has been observed. As constructing a sufficient number of natural disaster shelters is an important method for disaster emergency management [11], it is important to offer insights into how to use the site selection models, concerning natural disaster shelter selection and the affected people allocation, correctly. Therefore, the key aim of this paper is to review the study of natural disaster shelter location-allocation models to fill the gap 
in the research on site selection throughout the analysis of objectives, constraints, disaster types and approaches to solutions. In this paper, we present a brief depiction of different types of location-allocation models, according to the type of objectives and hierarchies. Then, the applications of these models in natural disasters, including hurricanes/typhoons, floods and earthquakes, are discussed. In addition, the approaches used to solve the models are analyzed and compared.

\section{Single-Objective Model}

Single-objective site selection problems are used to select or locate facilities, factories, warehouses, logistics centres, and shelters by determining the input parameters, such as the number of evacuees, the location, facility capacity, construction cost, and transportation cost, with the objective function being single and all parameters being certain and constant over time. This problem formed the basis for the multiobjective and hierarchical models. Single-objective site selection problems can be separated into three different types, depending on the objectives, namely, the $p$-median problem, the $p$-center problem and the covering problem, and detail definitions can be found in the corresponding section.

\section{1. $p$-Median Model}

The $p$-median problem was first proposed by Hakimi [5] in 1964. The problem was described as follows. In a communication network, such as a telephone interconnection system, there are usually a number of switching centers. All traffic flows (messages) within the network must arrive at one of the switching centers and then be processed and sent to their proper destination. The problem is to find the optimum locations for switching centers, such that the total length of wires is the minimum [12]. Moreover, the problem for facility site selection is how to determine the location of facilities, with the number of $p$, to make the sum of the weighted distance from all demands to the facilities the minimum. The $p$-median problem can ensure global benefits that are fair to all demands, and it is used widely in the site selection of factories and public facilities.

\subsubsection{Basic Model}

The mathematical model of the $p$-median problem was further synthetically formulated by ReVelle and Swain [13], as shown below.

$$
\begin{gathered}
\min \sum_{i \in I} \sum_{j \in J} c_{i j} x_{i j} \\
\text { s.t. } \sum_{j \in J} x_{i j}=1, \forall i \in I \\
x_{i j} \leq y_{j}, \forall i \in I, j \in J \\
\sum_{j \in J} y_{j}=p \\
x_{i j} \in\{0,1\}, y_{j} \in\{0,1\}, \forall i \in I, \forall j \in J
\end{gathered}
$$

where $I$ is the set of demand points. $J$ is the set of facilities. $x_{i j}$ indicates if facility $j$ is selected by demand point $i$ ( 1 if selected, 0 if not selected). $c_{i j}$ is the weighted distance from demand $i$ to facility $j$. $c_{i j}=w_{i} d_{i j}$, where $w_{i}$ is the weight of demand point $i$, and $d_{i j}$ is the shortest distance from demand $i$ to facility $j$. The objective of minimizing the sum weighted distance from all demands to the facilities is indicated by Equation (1). The constraint shown in Equation (2) indicates that one demand point can only be allocated to one facility. Equation (3) shows that facility $j$ can provide service to demand point $i$ only when it is opened. Equation (4) is the number constraint, which means the number of available facilities is $p$. 


\subsubsection{Capacitated $p$-Median Problem}

Considering the capacities and economic performances of facilities, the minimum capacity of a facility to be opened, and the maximum capacity of a facility, are added into the $p$-median model. Meanwhile, the number constraint of the $p$-median model is deleted. Consequently, the mathematical equations of the capacitated $p$-median problem are expressed below.

$$
\begin{gathered}
\min \sum_{i \in I} \sum_{j \in J} c_{i j} x_{i j} \\
\text { s.t. } \sum_{j \in J} x_{i j}=1, \forall i \in I \\
x_{i j} \leq y_{j}, \forall i \in I, j \in J \\
\sum_{i \in I} u_{i} x_{i j} \geq b_{j} y_{j}, \forall j \in J \\
\sum_{i \in I} u_{i} x_{i j} \leq B_{j} y_{j}, \forall j \in J \\
\sum_{k \in J \mid d_{i k} \leq d_{i j}} x_{i k} \leq y_{j}, \forall i \in I, j \in J \\
x_{i j} \in\{0,1\}, y_{j} \in\{0,1\}, \forall i \in I, \forall j \in J
\end{gathered}
$$

where $I$ is the set of demand points. $J$ is the set of facilities. $x_{i j}$ indicates if facility $j$ is selected by demand point $i$ ( 1 if selected, 0 if not selected). $c_{i j}$ is the weighted distance from demand point $i$ to facility $j$. $c_{i j}=u_{i} d_{i j}$, where $u_{i}$ is the population of demand $i . b_{j}$ and $B_{j}$ are the minimal and maximal capacity of facility $j$ to be opened. Compared with the $p$-median problem, the capacitated $p$-median problem mainly adds the constraints shown in Equations (9) and (10). Equation (11) is the closest-assignment constraint, which mandates that demands are served by their closest sited facility.

The $p$-median problem is one of the typical problems associated with minimizing the sum. According to the characters of the different site selections, there are various modifications of it. In addition to the capacitated $p$-median problem, stochastic models are used widely when selecting the locations of warehouses [14] and the assignment of relief vehicles and services [15]. It is used to solve the natural disaster shelter location problems, although it mainly considers disaster risk, and studies concerning natural disaster shelter location still mainly focus on deterministic models, with the objective of minimizing the sum of the distance or evacuation time. The $p$-median model is widely applied in the emergency shelter site selection of different types of disasters (Hurricanes/typhoons, floods, earthquakes, etc.), because evacuation distance/time is one of the most important factors for most disasters. In addition, the objective of the $p$-median model is global, which makes it suitable for most disasters, with a wide range of impacts after the disaster. Although this global objective ignores personal preferences, efficiency is prioritized, and it is relatively fair for all of the affected population.

Hurricanes/typhoons are periodic and can be predicted according to its characteristics. Thus, quick and safe evacuation is very important before these disasters happen, and the $p$-median model, with the objective of minimizing the sum of the distance or evacuation time, is always selected as the basic model to solve these problems. Sherali et al. [16] proposed a $p$-median shelter location model combined with a network model, with the objective of minimizing the evacuation time of the affected people to hurricane shelters, which considers the characteristics of hurricanes and solves it to obtain the locations of shelters and reasonable evacuation paths using the heuristic algorithm. Typhoon disasters always attack the coastal counties of Southeastern China and cause enormous losses. Therefore, Pan [17] analyzed the distribution of the population and building density in the counties and surveyed the demands of residents when meeting with typhoons. Then, a model of constructing county typhoon shelters was proposed, based on the $p$-median problem, and solved using a genetic algorithm, which provided a theoretical method for typhoons disaster prevention and reduction in the 
coastal counties. Kocatepe et al. [18] proposed a GIS-based capacitated $p$-median optimization model for hurricane shelter planning to maximize the accessibility and capacity of the existing shelters for 85+ populations with special needs (access and functional needs) or pets. Horner et al. [19] designed a GIS-based capacitated $p$-median model for the siting of special needs hurricane shelters to maximize accessibility for vulnerable populations, with a focus on the potential uncertainties in transportation network availability.

Kongsomsaksakul et al. [20] proposed a bilevel model to solve the flood shelter location problem, considering the interests of decision makers and evacuees. The upper model is based on the $p$-median problem, with the objective of minimizing the evacuation time. Gama et al. [21] presented a multiperiod location-allocation approach based on the capacitated $p$-median model, which considers that the travel times vary over time, depending on the road conditions. The objective is to minimize the overall network distances that evacuees have to travel in order to reach the shelters during flood disasters. People's reactions to the flood evolution are also considered to be dynamic. Moreover, a simulated annealing heuristic is proposed to solve the model.

Earthquakes are difficult to predict, and a large one could always cause serious injuries to people, which means that emergency shelters that can provide a safe place for people after the disaster are important. Meanwhile, earthquakes are influenced by various factors and always cause secondary disasters, which make it difficult to determine the locations of shelters. Nowadays, studies are mainly about constructing shelters in cities, such as Bayram et al. [22], who researched earthquake shelter locations and evacuation paths in Istanbul, based on the $p$-median problem, and analyzed the influence of capacities and numbers. Huang et al. [23] applied the $p$-median problem to shelter constructions that served people affected by earthquakes. Zhou et al. [24] analyzed the factors of distance and evacuation paths and established models based on the capacitated $p$-median problem.

\section{2. $p$-Center Model}

Hakimi [5] proposed the $p$-center problem for finding the optimum locations of police stations (or hospitals). Consider a number of communities of different sizes that are interconnected by a highway system. The $p$-center problem attempts to find the locations of the police stations $\mathrm{P}$, such that the maximum distance from $P$ is the minimum. The problem has the objective of minimizing the maximal distance from the demand points to the facilities when applied to facility site selection, as shown below.

$$
\begin{gathered}
\min r \\
\text { s.t. } \sum_{j \in J} d_{i j} x_{i j} \leq r \\
\sum_{j \in J} x_{i j}=1, \forall i \in I \\
x_{i j} \leq y_{j}, \forall i \in I, j \in J \\
\sum_{j \in J} y_{j}=p \\
x_{i j} \in\{0,1\}, y_{j} \in\{0,1\}, \forall i \in I, \forall j \in J
\end{gathered}
$$

where $i$ and $I$ are the index and set of demand points, respectively. $j$ and $J$ are the index and set of facilities, respectively. $x_{i j}$ indicates if the facility $j$ is selected by demand $i$ ( 1 is selected, 0 is not selected). $d_{i j}$ is the shortest distance from demand point $i$ to facility $j . r$ is the maximal one among the distances from all demands to the assigned facilities, which express fairness in meeting all demands. Equation (13) expresses the objective of minimizing the maximal distance from the demand points to the facilities. Equation (14) is the distance constraint. Equation (15) ensures that one demand point can only be allocated to one facility. Equation (16) ensures that demand points can only be allocated to the opened facilities. Equation (17) ensures the number of facilities is $p$. 
Elzinga and Hearn proposed a geometrical method to solve the problem for some minimax location problems in 1972, namely, the Elzinga-Hearn algorithm [25]. The application of the $p$-center model for emergency shelter site selection is not as popular as the $p$-median and covering models, as only one used it in the literature that we analyzed. It is Kilci et al. [26] who proposed a temporary shelter location model to select the best shelter locations from a set of criteria, with the objective of maximizing the minimum weight of open shelter areas. The model determines shelter locations and matches demands with the nearest open shelter while taking shelter area utilizations into account. The objective of the $p$-center model ignores global efficiency, and it is not suitable for most disasters with a wide range of impacts after the disaster. Thus, its applications are mainly focused on the site selection of fire stations, hospitals and so on to deal with local or individual events.

\subsection{Covering Model}

Although the $p$-median problem is widely used, there are some facilities that provide emergency services (fire stations, emergency centers, etc.) for which the $p$-median model is not suitable due to incomplete coverage of the demands. In addition, the $p$-median and $p$-center problems are concerned about the evacuation distance or time. However, the ignored factors, such as investment costs and the safety of people, are also important. To solve these problems, the covering model was proposed, which includes the set covering model and maximum covering model.

\subsubsection{Set Covering Model}

Toregas et al. [27] proposed the set covering problem, which determines the locations of facilities with minimum costs to cover all demands, in 1971. The model is described in Equations (19)-(21).

$$
\begin{gathered}
\min \sum_{j \in J} c_{j} x_{j} \\
\text { s.t. } \sum_{j=1}^{n} a_{i j} x_{j} \geq 1, \forall i \in I \\
x_{j} \in\{0,1\}, \forall j \in J
\end{gathered}
$$

where $i$ is the index of demands. $j$ is the index of facilities. $x_{j}$ indicates if the facility $j$ is selected $(1$ if selected, 0 if not selected). $c_{j}$ is the total costs for facility $j$ to be opened. $a_{i j}$ indicates if the distance from demand $i$ to facility $j$ is not more than $S$ ( 1 if is, 0 if is not). Equation (19) expresses the objective of minimizing the total cost, and Equation (20) ensures that each demand can be served by one facility at least.

\subsubsection{Maximal Covering Model}

To cover all demands described in the set covering model, more facilities are needed, which requires more resources and investments. However, sometimes, there are not enough resources and investments to cover all demands. As such, Church and Revell [28] proposed the maximal covering model, which meets as many demands as possible, with a fixed number of facilities. The mathematical Equations (22)-(27) show how the model works.

$$
\begin{gathered}
\max \sum_{i \in I} w_{i} y_{i} \\
\text { s.t. } \sum_{j \in J} x_{j}=p \\
y_{i} \leq \sum_{j \in J} a_{i j} x_{j}, \forall i \in I \\
x_{j} \in\{0,1\}, \forall j \in J
\end{gathered}
$$




$$
\begin{aligned}
& y_{i} \in\{0,1\}, \forall i \in I \\
& a_{i j}=\left\{\begin{array}{l}
1, d_{i j} \leq S \\
0, d_{i j}>S
\end{array}\right.
\end{aligned}
$$

where $i$ and $I$ are index and set of demands, respectively. $j$ and $J$ are the index and set of facilities, respectively. $w_{i}$ indicates the population or requirements of the demand points. $S$ is the maximal service distances of the facilities. $d_{i j}$ is the shortest distance from demand $i$ to facility $j . y_{i}$ indicates if demand $i$ is covered ( 1 if covered, 0 if not covered). $x_{j}$ indicates if the facility is opened ( 1 if opened, 0 if not opened). $a_{i j}$ indicates if the distance from demand $i$ to facility $j$ is not greater than $S$ ( 1 if not greater than, 0 if greater than). Equation (22) expresses the objective of maximizing the number of demand points covered by facilities. Equation (23) ensures that the number of opened facilities is $p$, and Equation (24) ensures that demand point $i$ is assigned to a selected facility within the given service distance limit.

\subsubsection{Generalized Maximal Covering Location}

For the maximal covering model, coverage is a binary that is not realistic for some applications. As a result, Berman and Krass [29] proposed the generalised maximal covering location problem, in which the demands are covered at different levels. It is formulated as follows:

$$
\begin{gathered}
\operatorname{maxh}(S)=\sum_{i=1}^{k} \sum_{i \in N(S, l)} w_{i} a_{i}^{l} \\
\text { s.t. } \sum_{j \in J} x_{j}=p \\
y_{i} \leq \sum_{j \in J} a_{i j} x_{j}, \forall i \in I \\
x_{j} \in\{0,1\}, \forall j \in J \\
y_{i} \in\{0,1\}, \forall i \in I \\
a_{i j}=\left\{\begin{array}{l}
1, d_{i j} \leq S \\
0, d_{i j}>S
\end{array}\right.
\end{gathered}
$$

where $i$ and $I$ are the index and set of demand points, respectively. $j$ and $J$ are the index and set of facilities, respectively. $w_{i}$ indicates the population number or requirements of demand points, and $S$ is the maximal service distances of facilities. $d_{i j}$ is the shortest distance from demand $i$ to facility $j . y_{i}$ indicates if demand $i$ is covered ( 1 if covered, 0 if not covered). $x_{j}$ indicates if the facility is opened ( 1 if opened, 0 if not opened). $a_{i j}$ indicates if the distance from demand $i$ to facility $j$ is not greater than $S$ ( 1 if not greater than, 0 if greater than). In the objective of Equation (28), $a_{i}^{l}$ is the coverage level, which means that the demand points can be covered at different levels, according to the distance from the demand points to the facilities.

It can be seen from the definition and characteristics of the covering model that it is applicable to the disaster shelter site selection problem, and many multiobjective models and hierarchical models are built on it. The applications of the single-objective covering site selection model in emergency shelters for different types of disasters are as follows:

Dalal et al. [30] analyzed typhoon shelters based on the set covering model, with the objective of minimizing the number of shelters covering all villages and the constraints of capacity and distance. Then, it was solved using the cluster method. Pan et al. [31] added a capacity factor to the maximal covering model and applied it to the typhoon shelter location problem. 
Gama et al. [32] proposed a dynamic maximal covering model based on the modified maximal model proposed by Berman and Krass [29], considering other rescue facilities, path conditions and the depth and speed of flood water. In their study, the evacuation time and covered demands varied over time, depending on the road conditions and the flood dynamics. Thus, they calculated the locations and number of opened shelters and the allocation of evacuees in the different periods using the model.

Ye et al. [33] assigned the service radius of the earthquake shelters, with objective of maximizing the coverage of the population demand, analyzing the capacity and allocation situation of current earthquake shelters in the Lujiazui street of Shanghai in China. Zhou and Jian [34] added a new factor, named the second distance, into the maximal covering model and established the location selection model to help provide other choices when the expected shelters could not be used in Taizhong city, Taiwan, China. Additionally, Zhao et al. [35] applied a model that is based on the capacitated set covering model for the earthquake shelter setting in Huangpu District of Shanghai in China and analyzed the change of the number of evacuees with the change of the time of the earthquake occurrence. Hu et al. [36] proposed a set covering model, with the objective of minimizing the number of shelters, while satisfying the capacity constraint and distance constraint, and applied it to the earthquake shelter location-allocation problem in Zhuguang Block in the south of the Yuexiu District of Guangzhou, China after solving it with the modified particle swarm optimization (PSO) algorithm. Ma et al. [37] developed a capacitated set covering single-objective model and a bilevel model and compared the allocation results of residents to the earthquake shelters, with the case study of Rongcheng of Shandong province, China.

\subsection{Summary of the Single-Objective Model}

From the examination of the single-objective site selection problems, the classification of the site selection problems, objectives, constraints, methods for solutions and targeted hazards associated with the natural disaster shelter location-allocation optimization model were summarized (Table 2).

As shown in Table 2, the $p$-median model, with the objective of minimizing the sum of distance or evacuation time, is widely applied in the emergency shelter site selection of different types of disasters (all Hurricanes, half of the others), because evacuation distance/time is one of the most important factors for most disasters. In addition, the objective of the $p$-median model is global, which makes it suitable for most disasters with a wide range of impacts after the disaster. Although this global objective ignores personal preferences, efficiency is prioritized, and it is relatively fair to all of the affected population.

There are very few applications of the $p$-center model for emergency shelter site selection. This is because the objective of the $p$-center model ignores global efficiency, and it is not suitable for most disasters with a wide range of impacts after the disaster. Its applications mainly focus on the site selection of fire stations, hospitals and so on to deal with local or individual events.

The covering model is applicable to the disaster shelter site selection problem, especially for some emergency service facilities, including emergency shelters, fire stations and emergency centers that need cover all of the demands, due to its characteristics and definition. Thus, its applications for different targeted hazards occupied almost half of the listed literature. 
Table 2. Classification of the objectives, constraints, methods for solutions and targeted hazards of the single-objective model for the shelter location and allocation.

\begin{tabular}{|c|c|c|c|c|c|c|c|c|c|c|c|c|c|}
\hline \multirow{3}{*}{ Authors } & \multirow{3}{*}{$\begin{array}{l}\text { Classification of } \\
\text { Site Selection } \\
\text { Models }\end{array}$} & \multicolumn{7}{|c|}{ Objective } & \multicolumn{3}{|c|}{ Constraint } & \multirow{3}{*}{$\begin{array}{l}\text { Method for Solutions or Optimization } \\
\text { Software Package }\end{array}$} & \multirow{3}{*}{$\begin{array}{l}\text { Targeted } \\
\text { Hazard }\end{array}$} \\
\hline & & \multicolumn{5}{|c|}{ Minimum } & \multirow{2}{*}{$\begin{array}{c}\text { Maximin } \\
\text { Weight }\end{array}$} & \multirow{2}{*}{$\frac{\text { Maximal }}{\text { Cover }}$} & \multirow{2}{*}{ Capacity } & \multirow{2}{*}{ Distance } & \multirow{2}{*}{ Number } & & \\
\hline & & Distance & Time & Risk & Cost & Number & & & & & & & \\
\hline Sherali et al. [16] & $p$-median & & $\sqrt{ }$ & & & & & & $\sqrt{ }$ & & & $\begin{array}{l}\text { Heuristic and an exact implicit enumeration } \\
\text { algorithm based on the generalized Benders' } \\
\text { decomposition method }\end{array}$ & Hurricane \\
\hline $\begin{array}{l}\text { Widener [38], Widener } \\
\text { and Horner [39] }\end{array}$ & $p$-median & $\sqrt{ }$ & & & & & & & $\sqrt{ }$ & $\sqrt{ }$ & & CPLEX & Hurricane \\
\hline Kocatepe et al. [18] & $p$-median & & & & $\checkmark$ & & & & $\sqrt{ }$ & & $\sqrt{ }$ & GIS-based method & Hurricane \\
\hline Horner et al. [19] & $p$-median & & & & $\sqrt{ }$ & & & & $\sqrt{ }$ & & $\sqrt{ }$ & GIS-based method & Hurricane \\
\hline $\begin{array}{l}\text { Dalal et al. [30] } \\
\text { Pan [17] }\end{array}$ & $\begin{array}{l}\text { Set covering } \\
p \text {-median }\end{array}$ & $\sqrt{ }$ & & & & $\sqrt{ }$ & & & $\sqrt{ }$ & $\sqrt{ }$ & & $\begin{array}{l}\text { Elzinga-Hearn algorithm } \\
\text { Genetic algorithm (GA) }\end{array}$ & $\begin{array}{l}\text { Typhoon } \\
\text { Typhoon }\end{array}$ \\
\hline Pan [31] & $\begin{array}{l}\text { Maximal } \\
\text { covering }\end{array}$ & & & & & & & $\sqrt{ }$ & & & $\sqrt{ }$ & Exact algorithm & Typhoon \\
\hline $\begin{array}{l}\text { Kongsomsaksakul et al. } \\
{[20]}\end{array}$ & $p$-median & & $\sqrt{ }$ & & & & & & $\sqrt{ }$ & & & GA & Flood \\
\hline Gama et al. [32] & $\begin{array}{l}\text { Maximal } \\
\text { covering }\end{array}$ & & & & & & & $\sqrt{ }$ & $\sqrt{ }$ & $\sqrt{ }$ & $\sqrt{ }$ & CPLEX 12.5 & Flood \\
\hline Gama et al. [21] & $p$-median & $\sqrt{ }$ & & & & & & & $\sqrt{ }$ & & $\sqrt{ }$ & Simulated annealing algorithm (SA) & Flood \\
\hline Zhou and Jian [34] & $\begin{array}{l}\text { Maximal } \\
\text { covering }\end{array}$ & & & & & & & $\sqrt{ }$ & $\sqrt{ }$ & $\sqrt{ }$ & $\sqrt{ }$ & Exact algorithm & Earthquake \\
\hline Huang et al. [23] & $p$-median & $\sqrt{ }$ & & & & & & & & & $\sqrt{ }$ & GA & Earthquake \\
\hline Zhou et al. [24] & $p$-median & $\sqrt{ }$ & & & & & & & $\sqrt{ }$ & & $\checkmark$ & Exact algorithm & Earthquake \\
\hline Hu et al. [36] & Set coving & & & & & $\sqrt{ }$ & & & $\sqrt{ }$ & $\sqrt{ }$ & & Modified particle swarm optimization (PSO) & Earthquake \\
\hline Ye et al. [33] & $\begin{array}{l}\text { Maximal } \\
\text { covering }\end{array}$ & & & & & & & $\sqrt{ }$ & $\sqrt{ }$ & & & Spatial analysis techniques of GIS & Earthquake \\
\hline $\begin{array}{l}\text { Zhao et al. [35] } \\
\text { Bavram et al. [22] }\end{array}$ & Set coving & & d & & $\sqrt{ }$ & & & & $\sqrt{ }$ & J & ل & $\begin{array}{c}\text { CPLEX 12.4 } \\
\text { Second order cone prooramming approach }\end{array}$ & $\begin{array}{l}\text { Earthquake } \\
\text { Earthquake }\end{array}$ \\
\hline K1lc1 et al. [26] & $p$-center & & & & & & $\sqrt{ }$ & & $\sqrt{ }$ & & & $\begin{array}{c}\text { Network Analyst extension of ESRI ArcGIS } \\
\text { Desktop }\end{array}$ & Earthquake \\
\hline Ma et al. [37] & Set coving & $\sqrt{ }$ & & & & & & & $\sqrt{ }$ & $\sqrt{ }$ & & Modified PSO & Earthquake \\
\hline Berman and Krass [29] & $\begin{array}{l}\text { Maximal } \\
\text { covering }\end{array}$ & & & & & & & $\sqrt{ }$ & & & $\sqrt{ }$ & $\begin{array}{l}\text { Greedy heuristic, special-purpose IP } \\
\text { algorithms }\end{array}$ & General \\
\hline $\begin{array}{l}\qquad \mathrm{Li} \mathrm{[40]} \\
\text { Bozorgi-Amiri et al. [41] }\end{array}$ & $\begin{array}{l}p \text {-median } \\
\text { Set coving }\end{array}$ & & $\sqrt{ }$ & & ل & & & & $\sqrt{ }$ & $\sqrt{ }$ & & $\begin{array}{l}\text { Interactive method } \\
\text { Modified PSO }\end{array}$ & $\begin{array}{l}\text { General } \\
\text { General }\end{array}$ \\
\hline Yuan et al. [42] & $\begin{array}{l}\text { Maximal } \\
\text { covering }\end{array}$ & & & & & & & $\sqrt{ }$ & & & $\sqrt{ }$ & Modified GA & General \\
\hline $\mathrm{Du}[43]$ & $p$-median & $\sqrt{ }$ & & & & & & & & & & Ant colony optimisation algorithm (ACO) & General \\
\hline
\end{tabular}




\section{Multiobjective Model}

A single-objective model is too simplistic to effectively address the location-allocation problem for emergency shelters, because it often ignores important objectives [44]. To solve the more complex problems, multiobjective models, based on the $p$-median problem, the $p$-center problem, the covering problem, and so on, are developed. For example, Barzinpour and Esmaeili [45] developed the multiobjective mixed-integer linear programming model, with the objectives of maximizing the population coverage and minimizing the construction costs and traffic costs by using a virtual zoning approach to achieve humanitarian and financial goals. From the examination of the multiobjective site selection problems, the objectives, constraints, disaster types and methods for solutions associated with the natural disaster shelter location-allocation optimization model were summarized (Table 3). Moreover, the applications of the multiobjective site selection model for emergency shelters for different types of disasters are as follows:

Alçada-Almeida et al. [46] selected four objectives: Minimizing the total distance from the demand points to the shelters; minimizing the total risk of the evacuation paths unconnected to a hospital; minimizing the fire risk in the shelters; and minimizing the total time from the shelters to the University Hospital. They then proposed a model based on the $p$-median model for evacuation during major fires and solved it using the framework of a web-based decision support system. There were two objectives in this: Minimizing the total travel distance for backup paths and minimizing the total number of shelters, which were also considered in the multiobjective model in their following work [47].

Doerner et al. [48] proposed a tsunami disaster shelter location model, with the objectives of minimizing the weighted average of the minimal and maximal distance, the risk of hurricanes and costs. They developed a heuristic solution technique, based on the Nondominated Sorting Genetic Algorithm II (NSGA-II), to solve the multiobjective optimization of facility location decisions, taking tsunami hazards into account.

Yushimito et al. [49] were looking to maximize the coverage of the affected regions, while minimizing human suffering, through the use of a deprivation function based on distance, as a proxy of social cost, to create an uncapacitated nonlinear optimization model. They provided an application example using data from Hurricane Katrina. Additionally, they presented an algorithm to find the best Voronoi diagram, and within the algorithm, they proposed the use of the Nelder-Mead-based solution for nonlinear subproblems along with the proportional sampling technique to find the initial points for the heuristic.

Based on the scenarios, Rodríguez-Espíndola and Gaytán [49] checked the flood areas by using GIS and proposed a model, with the objective of minimizing distance and costs, and solved it using CPLEX 11.0 with the weighted-sum method. To cover both earthquake and flood risks, Nolz et al. [50] developed a multiobjective optimization model. The three objective functions were the measures of risk, coverage, and total travel time. Additionally, a memetic algorithm based on the NSGA-II was proposed as the approach for solutions.

Wu and Wong [51] set up an earthquake shelter location model, with the objectives of minimizing the evacuation distance, minimizing the maximal utility rate of shelters and minimizing the number of shelters. Hu et al. [52] developed an earthquake shelter location-allocation model, with the objectives of minimizing the total distance from communities to shelters and the total cost, and solved it using a genetic algorithm. Zhao et al. [53,54] introduced an earthquake shelter allocation model, with the objectives of minimizing the total weighted evacuation time and the total area of shelters, and solved it using a modified PSO algorithm combined with the SA algorithm. Zhou et al. [55] proposed a multiobjective urban shelter location planning model, which comprehensively considered the principles of fairness and efficiency in the location selection by integrating the maximum coverage model and the $p$-median model. The modeling was solved in the optimization software, Linear Interactive and General Optimizer (LINGO), and the model was applied in the Tianjin earthquake shelter location planning. Ma et al. [56] developed a multiobjective model for the allocation of residents to earthquake shelters using Wenchang of Hainan province, China as a case study. 
Table 3. Objectives, constraints, methods for solutions and targeted hazards of the multiobjective model for shelter location and allocation.

\begin{tabular}{|c|c|c|c|c|c|c|c|c|c|c|c|c|c|c|c|c|c|c|}
\hline \multirow[b]{3}{*}{ Authors } & \multicolumn{10}{|c|}{ Objective } & \multicolumn{6}{|c|}{ Constraint } & \multirow[b]{3}{*}{$\begin{array}{l}\text { Method for Solutions or Optimization } \\
\text { Software Package }\end{array}$} & \multirow[b]{3}{*}{ Targeted Hazard } \\
\hline & \multicolumn{5}{|c|}{ Minimum } & & \multirow{2}{*}{$\begin{array}{l}\text { Maximin } \\
\frac{\overrightarrow{7}}{300} \\
3 \\
3\end{array}$} & \multirow[b]{2}{*}{$\begin{array}{c}\text { Minimax } \\
\vec{c} \\
\frac{\vec{c}}{.00} \\
3 \\
3\end{array}$} & \multicolumn{2}{|c|}{ Maximal } & \multirow[b]{2}{*}{ 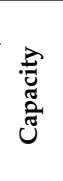 } & \multirow[b]{2}{*}{ 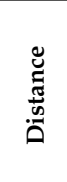 } & \multirow[b]{2}{*}{ 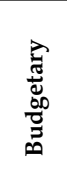 } & \multirow[b]{2}{*}{ 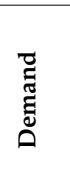 } & \multirow[b]{2}{*}{ } & \multirow[b]{2}{*}{ 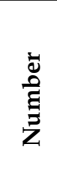 } & & \\
\hline & 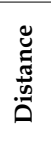 & 菣 & $\frac{\breve{m}}{\ddot{n}}$ & نे & 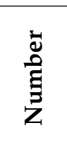 & 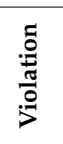 & & & 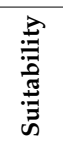 & 亗 & & & & & & & & \\
\hline Alçada-Almeida et al. [46] & $\sqrt{ }$ & $\sqrt{ }$ & $\sqrt{ }$ & & & & & & & & $\sqrt{ }$ & & & & & $\sqrt{ }$ & GIS-based decision support system & Fire \\
\hline Coutinho-Rodrigues et al. [47] & $\sqrt{ }$ & $\sqrt{ }$ & $\sqrt{ }$ & & $\sqrt{ }$ & & & & & & $\sqrt{ }$ & & & & & & GIS-based decision support system & Fire \\
\hline Doerner et al. [48] & $\checkmark$ & & $\sqrt{ }$ & $\sqrt{ }$ & & & & & & & $\checkmark$ & $\sqrt{ }$ & & & & & NSGA-II & Tsunami \\
\hline Yushimito et al. [57] & & & & $\sqrt{ }$ & & & & & & $\sqrt{ }$ & & & & & & & Voronoi-based heuristic algorithm & Hurricane \\
\hline Nolz et al. [50] & & $\sqrt{ }$ & $\sqrt{ }$ & & & & & & & $\sqrt{ }$ & $\sqrt{ }$ & $\sqrt{ }$ & & & & & Memetic algorithm based on NSGA-II & $\begin{array}{l}\text { Flood and } \\
\text { earthquake }\end{array}$ \\
\hline Tzeng et al. [58] & & $\sqrt{ }$ & & $\checkmark$ & & & $\sqrt{ }$ & & & & $\sqrt{ }$ & & & & & & Fuzzy multiobjective programming & Earthquake \\
\hline Wu and Wong [51] & $\sqrt{ }$ & & & & $\sqrt{ }$ & & & $\sqrt{ }$ & & & $\sqrt{ }$ & $\sqrt{ }$ & & & & & GIS-based decision support system & Earthquake \\
\hline Zhao et al. [53] & & & & & & & & & & & $\sqrt{ }$ & & & & & & NSGA-II & Earthquake \\
\hline Zhao et al. [54] & & $\sqrt{ }$ & & $\sqrt{ }$ & & & & & & & $\sqrt{ }$ & $\sqrt{ }$ & & & & & Modified PSO & Earthquake \\
\hline Xu et al. [44] & $\sqrt{ }$ & & & $\sqrt{ }$ & & & & & & & $\sqrt{ }$ & $\sqrt{ }$ & & & & & Modified PSO & Earthquake \\
\hline Xu et al. [59] & $\sqrt{ }$ & $\sqrt{ }$ & & $\sqrt{ }$ & $\sqrt{ }$ & & & & & & $\sqrt{ }$ & $\checkmark$ & & & & & Modified PSO & Earthquake \\
\hline Zhou et al. [55] & $\sqrt{ }$ & & & & & & & $\sqrt{ }$ & & $\sqrt{ }$ & & & & & & $\sqrt{ }$ & LINGO & Earthquake \\
\hline Ma et al. [56] & $\sqrt{ }$ & & & $\sqrt{ }$ & & & & & & & $\sqrt{ }$ & $\sqrt{ }$ & & & & & Modified PSO & Earthquake \\
\hline $\begin{array}{l}\text { Saadatseresht et al. [62] } \\
\text { Bozorgi-Amiri et al. [63] }\end{array}$ & & & & $\sqrt{ }$ & & $\sqrt{ }$ & & $\begin{array}{l}\sqrt{ } \\
\sqrt{ }\end{array}$ & & & $\sqrt{ }$ & $\sqrt{ }$ & & & & & $\begin{array}{c}\text { NSGA-II } \\
\text { Lp-metrics technique }\end{array}$ & $\begin{array}{l}\text { General } \\
\text { General }\end{array}$ \\
\hline Zhang et al. [64] & & & & $\sqrt{ }$ & & & & $\sqrt{ }$ & & & & & & & & & $\begin{array}{l}\text { Stochastic diffusion search based intelligent } \\
\text { algorithm }\end{array}$ & General \\
\hline Barzinpour and Esmaeili [45] & & & & $\sqrt{ }$ & & & & & & $\sqrt{ }$ & $\sqrt{ }$ & & & & & & LINGO 9.0 based on virtual zoning approach & General \\
\hline Jalali et al. [65] & & & & $\sqrt{ }$ & & & & & & $\sqrt{ }$ & $\sqrt{ }$ & $\sqrt{ }$ & & & & & $\begin{array}{l}\text { Multiobjective biogeography-based optimization } \\
\text { algorithm (MOBBO) }\end{array}$ & General \\
\hline $\begin{array}{l}\text { Trivedi and Singh [66] } \\
\text { Haghi et al. [67] }\end{array}$ & $\sqrt{ }$ & & $\sqrt{ }$ & $\sqrt{ }$ & $\sqrt{ }$ & & & $\sqrt{ }$ & $\sqrt{ }$ & $\sqrt{ }$ & $\sqrt{ }$ & & $\sqrt{ }$ & $\sqrt{ }$ & $\sqrt{ }$ & & $\begin{array}{l}\text { Fuzzy AHP and goal programming } \\
\text { Combination of GA and SA }\end{array}$ & $\begin{array}{l}\text { General } \\
\text { General }\end{array}$ \\
\hline
\end{tabular}


The two objectives of the multiobjective model were to minimize the total evacuation distance and to minimize the total area of all shelters, with the constraints of shelter capacity and service radius. The modified PSO algorithm was used to solve the model.

\section{Hierarchical Model}

There are two main types of hierarchical model. One works according to the functions of the facilities at different levels (called the general hierarchical model). The other one is the bilevel model whose upper level works to select the locations of shelters and lower level works to assign the evacuation paths.

\subsection{General Hierarchical Model}

Beginning as early as 1979 in a work by Narula and Ogbu [68] on location-allocation problems, hierarchical facilities traditionally refer to an interrelated structure of facility classifications, wherein only the lowest level of facilities services demands, the next higher level of facilities supports the lowest level of facilities, and so forth. A hierarchical capacitated-median location model, based on the temporal hierarchy of shelters, can be formulated as follows:

$$
\begin{gathered}
\min \sum_{i \in I} \sum_{j \in J} \sum_{s \in S} c_{i j} x_{i j s} \\
\text { s.t. } \sum_{j \in J} x_{i j s}=1, \forall i \in I, \forall s \in S \\
x_{i j s} \leq \sum_{t \in S \mid t \geq s} y_{j t}, \forall i \in I, \forall j \in J, \forall s \in S \\
\sum_{s \in S} y_{j s} \leq 1, \forall j \in J \\
\sum_{t \in S \mid t \geq s} \sum_{i \in I} u_{i t} x_{i j t}=\sum_{s \in S} \sum_{i \in I} u_{i s} x_{i j s}, \forall j \in J \\
\sum_{i \in I} u_{i s} x_{i j s} \geq b_{j s} y_{j s}, \forall j \in J, \forall s \in S \\
\sum_{i \in I} u_{i s} x_{i j s} \leq B_{j s} y_{j s}, \forall j \in J, \forall s \in S \\
\sum_{i k s} \geq y_{j t}, \forall i \in I, j \in J, s \in S, \forall t \in S \mid t \geq s \\
x_{k \in J \mid d_{i k} \leq d_{i j}} \\
x_{i j s} \in\{0,1\}, y_{j s} \in\{0,1\}, \forall i \in I, j \in J
\end{gathered}
$$

where $I$ is the set of demand points. $J$ is the set of facilities. $x_{i j s}$ indicates if a type-s facility $j$ is selected by demand point $i$ ( 1 if selected, 0 if not selected). $c_{i j}$ is the weighted distance from demand point $i$ to facility $j . c_{i j}=u_{i s} d_{i j}$, where $u_{i s}$ is the population number of demand $i$ for a type-s facility. $b_{j s}$ and $B_{j s}$ are the minimal and maximal capacity of a type-s facility $j$ to be opened. The constraint (Equation (36)) assures that the demand of level $s$ is served by a facility of level $s$ or higher. The constraint (Equation (37)) keeps any two facilities of the same type or different types from being assigned to the same location, preventing facility co-location. Equation (38) helps to ensure that all affected people will be served by facilities of different levels at each evacuation phase. The minimum and maximum levels of capacity restriction for different facility types are constrained by Equations (39) and (40). Equation (41) is the closest assignment constraint, which mandates that demand nodes are served by their closest facility. 
General hierarchical models have been widely studied in the field of health-care systems, solid waste management systems, production-distribution systems, education systems, emergency medical service systems, and telecommunications networks [69], as well as express delivery services, fire protection, and area planning [70]. However, they are rarely involved in disaster shelter site selections. To the best of our knowledge, the applications of the general hierarchical site selection model for emergency shelters for different types of disasters are as follows:

Widener $[38,39]$ divided the relief shelters in Leon County, Florida, USA, into different levels. The basic supplies are provided by the shelters at the lowest level, and the specialised supplies are provided by the highest level. Then, the hierarchical capacity model was developed, with the objective of minimizing the distance from all demand points to facilities and applied to solve the location-allocation problem of hurricane disasters.

Chen et al. [71-73] proposed a three-level hierarchical model, based on the shelter functions at different evacuation phases, for solving earthquake shelter location problems. Li [74] developed a hierarchical location-allocation model, based on the set covering model for earthquake emergency shelters. However, the model did not consider the capacity constraints of shelters, and as a result, the complexity of the problem was greatly reduced. Therefore, the GIS technology was used to solve the relatively simple location-allocation optimization problem. Li et al. [75] established a three-level location-allocation model for immediate, short-term and long-term shelters, considering the hierarchical characteristics of evacuation demand and shelter system. A p-median model, with the objective of minimizing the evacuation distance, was developed for the immediate and short-term evacuation phase. A maximal covering model was built for the long-term evacuation phase to cover the maximum demand. The three-level hierarchical model considered distance and capacity constraints to solve the optimization problem of Yanjiao Town in Hebei Province, China using LINGO software. Li et al. [76] considered hierarchical emergency shelter planning for earthquake disasters in urban areas, taking into consideration the estimation of time-varying refuge demand. Then, they formulated an integrated location-allocation model that was used sequentially: an emergency shelter location model to satisfy the time-varying shelter demand, with the objective of minimizing the total setup cost of locating the shelters, and an allocation model that allocated the evacuees to shelters, with the objective of minimizing their total evacuation distance [10]. Most recently, Ma et al. [77] adopted a multi-level coverage and supplemental site selection concept to establish a hierarchical supplemental location-allocation model for preparedness and response phases that can minimize the total number and cost for the facility location problem and the total distance at all levels for the supply allocation problem.

\subsection{Bilevel Model}

Bilevel programming is a two-level hierarchical optimization problem, where one problem is nested within another [78]. The first formulation of bilevel programming problems, by H.v. Stackelberg [79] on the market economy, dates back to 1934. The Stackelberg leader-follower games are a classic example of bilevel programming problems [80]. The upper level problem is referred to as the leader problem, while the lower level is referred to as the follower problem [81]. Bilevel programming problems were introduced to the optimization community in the seventies of the 20th century [82-84]. After that moment, a rapid development and intensive investigation of bilevel optimization began, both in theoretical and in application-oriented directions. Contributions to its investigation have been delivered by mathematicians, economists and engineers, and the number of papers within this field is ever growing rapidly. For example, Fisk [85] highlighted the relation between the Stackelberg game and transportation system modelling for the first time in 1984 and presented the typical formulation of a bilevel optimization problem as follows:

$$
\begin{gathered}
\left(P_{1}\right) \min _{u} F(u, v(u)) \\
\text { s.t.G }(x, y) \leq 0
\end{gathered}
$$


where $v$ solves

$$
\begin{aligned}
& \left(P_{2}\right) \min _{v} f(u, v) \\
& \text { s.t.g }(u, v) \leq 0
\end{aligned}
$$

where $F$ is the objective function of the upper level problem $P_{1}$ (Equation (43)); and $u$ and $G$ are the decision vector and the constraint set of the upper level problem (Equation (44)), respectively. $f$ is the objective function of the lower level problem $\mathrm{P}_{2}$ (Equation (45)); and $v$ and $g$ are the decision vector and the constraint set of the lower level problem (Equation (46)), respectively. The upper level problem models the decision of the leader in the game, while the lower level problem models the decision of the follower. In the bilevel location-allocation model, the leader cannot control the behavior of the follower, but can influence the behavior of the follower by choosing the number and location of shelters. The respective levels communicate information to one another, and they influence each other's result sets. This reflects the bilevel nature of the formulation.

The vast majority of the existing site section models assume that people will follow the system optimal routes prescribed to them (cooperative behavior), although recent research has shown that this may not be realistic, because people tend to prioritize self-interest (non-cooperative behavior) during large evacuations $[44,86,87]$. To simulate the sequential nature of evacuation processes (central planner determines the shelter assignment, after which evacuees are free to choose their own routes based on the shelter they are assigned to), the bilevel model was presented, which balances the planner's objective and residents' behavior, incorporating both system and user optimal elements. As an example of the typical bilevel model for location and allocation problems, several bilevel models, simulating the strackelberg game theory, were set up $[20,88,89]$, in which the leader's upper-level program is the shelter location selection made by decision makers, and the follower's lower-level program is the evacuation path choices made by evacuees.

A large amount of research has been conducted on bilevel optimization problems, both in the realm of algorithms for different optimization problems (linear or non-linear; convex or non-convex; continuous or discontinuous) and applications, especially in the fields of mathematical programming and evolutionary computing. However, the multiobjective extensions of bilevel programming have received relatively little attention from researchers, especially the application of a real-world optimization problem, which contains a large number of parameters and several objective functions. Multiobjective optimization and bilevel programming have been combined as multiobjective bilevel optimization in some works. Particularly, there are three different ways to integrate both techniques: (i) models with the multiobjective optimization in the upper level problem [90-92]; (ii) models with the multiobjective optimization in the lower-level problem [93-97]; and (iii) models with the multiobjective optimization both in the upper-level and lower-level problems [98-104].

Bilevel models are applied mostly to deal with evacuation before disasters, such as hurricanes and floods, rather than other disasters, and are often combined with traffic network models [20,105-107]. The applications of the bilevel site selection model in emergency shelters for different types of disasters are as follows:

$\mathrm{Ng}$ et al. [105] presented a hybrid bilevel model (in the upper level, shelter assignment occurs in a system optimal fashion, whereas evacuees are free to choose how to reach their assigned shelters in the lower level) under hurricane conditions, hence providing a model that was more consistent with the current state of knowledge of human behavior during disasters. The proposed model was solved using a simulated annealing algorithm. Li et al. [107] developed a stochastic bilevel model based on scenarios. The upper level is a stochastic model with two stages, in which the shelter locations are determined in the first stage and the opened shelters are selected in the second stage, according to the hurricane situation. Then, on the lower level, evacuees respond according to the result of the upper level to select the evacuation paths. Additionally, Li et al. [106] developed a stochastic bilevel model with a preparation stage and response stage, according to the disaster scenarios, and solved it by using an L-shaped algorithm to solve the hurricane shelter location problem in America. 
Kongsomsaksakul et al. [20] proposed a bilevel model to solve the flood shelter location problem, in consideration of the interests of decision makers and evacuees. The upper model is based on the $p$-median problem with the objective of minimizing the evacuation time, the evacuees in the lower model try to travel to safe shelters with the least travel time.

$\mathrm{Xu}$ et al. [44] developed a scenario-based hybrid bilevel model that addresses the concerns related to high-dimensional complexity and provided a higher degree of realism by incorporating the uncertainties of the population dynamics and earthquake damage scenarios into location-allocation problems for earthquake emergency shelters. A modified PSO algorithm, combined with an SA algorithm, was applied to derive solutions using the hybrid bilevel model and a conventional multiobjective model, and the solutions obtained using the two models were then compared.

\subsection{Summary of the Hierarchical Model}

From the examination of the hierarchical site selection problems, the objectives, constraints, disaster types and methods for solutions associated with the natural disaster shelter location-allocation optimization model were summarized (Table 4).

In recent years, general hierarchical models have been widely studied in the field of health-care systems, solid waste management systems, production-distribution systems, education systems, emergency medical service systems, and telecommunications networks [69], as well as express delivery services, fire protection, and area planning [70]. However, they are relatively less involved in disaster shelter site selections. Among them, most of the researches focus on earthquake disasters, and research on floods, typhoons and other disasters is lacking.

The bilevel model is a two-level hierarchical optimization model, where one problem is nested within another, and it performs well in solving complex, high-dimensional problems, providing a higher degree of realism [44]. It balances the planner's objective and residents' behavior to incorporate both system and user optimal elements. Bilevel models are applied mostly to deal with evacuation before disasters, such as hurricanes and floods, rather than other disasters, and are often combined with traffic network models [20,105-107]. They are rarely involved in earthquake disaster shelter site selections, and the application research on different disaster types, especially using multiobjective bilevel model, would be one of the main directions of future research on disaster shelter location-allocation problems. 
Table 4. Objectives, constraints, methods for solutions and targeted hazards of the hierarchical model for shelter location and allocation

\begin{tabular}{|c|c|c|c|c|c|c|c|c|c|c|c|c|c|c|}
\hline \multirow{3}{*}{ Author } & \multirow{3}{*}{$\begin{array}{l}\text { Classification } \\
\text { of Site } \\
\text { Selection } \\
\text { Models } \\
\end{array}$} & \multicolumn{6}{|c|}{ Objective } & \multicolumn{5}{|c|}{ Constraint } & \multirow{3}{*}{$\begin{array}{c}\text { Method for Solutions or } \\
\text { Optimization Software Package }\end{array}$} & \multirow{3}{*}{$\begin{array}{l}\text { Targeted } \\
\text { Hazard }\end{array}$} \\
\hline & & \multicolumn{5}{|c|}{ Minimum } & \multirow{2}{*}{$\begin{array}{c}\text { Maximal } \\
\text { Cover }\end{array}$} & \multirow{2}{*}{ Capacity } & \multirow{2}{*}{ Distance } & \multirow{2}{*}{ Budgetary } & \multirow{2}{*}{ Demand } & \multirow{2}{*}{ Number } & & \\
\hline & & Distance & Time & Risk & Cost & Number & & & & & & & & \\
\hline $\begin{array}{l}\text { Widener [38], Widener } \\
\text { and Horner [39] }\end{array}$ & $\begin{array}{c}\text { General } \\
\text { hierarchical }\end{array}$ & $\sqrt{ }$ & & & & & & $\sqrt{ }$ & $\sqrt{ }$ & & & & CPLEX & Hurricane \\
\hline $\begin{array}{l}\text { Chen et al. [71,72] } \\
\text { Chen et al. [73] }\end{array}$ & $\begin{array}{c}\text { General } \\
\text { hierarchical }\end{array}$ & $\sqrt{ }$ & & & & & & $\sqrt{ }$ & & $\sqrt{ }$ & & & GIS context & Earthquake \\
\hline Li et al. [76] & $\begin{array}{c}\text { General } \\
\text { hierarchical }\end{array}$ & $\sqrt{ }$ & & & $\sqrt{ }$ & & & $\sqrt{ }$ & $\sqrt{ }$ & & & & Hybrid cross-entropy method & Earthquake \\
\hline Zhao et al. [10] & $\begin{array}{c}\text { General } \\
\text { hierarchical }\end{array}$ & $\sqrt{ }$ & & & $\sqrt{ }$ & & & $\sqrt{ }$ & $\sqrt{ }$ & & & & $\begin{array}{c}\text { Cross-entropy with a local search } \\
\text { mechanism }\end{array}$ & Earthquake \\
\hline Li [74] & $\begin{array}{c}\text { General } \\
\text { hierarchical }\end{array}$ & & & & $\sqrt{ }$ & & & & $\sqrt{ }$ & & & & GIS & Earthquake \\
\hline Li [75] & $\begin{array}{l}\text { General } \\
\text { hierarchical }\end{array}$ & $\sqrt{ }$ & & & & & $\sqrt{ }$ & $\sqrt{ }$ & $\sqrt{ }$ & & & & LINGO & Earthquake \\
\hline Paul et al. [108] & $\begin{array}{c}\text { General } \\
\text { hierarchical }\end{array}$ & & & & $\sqrt{ }$ & & $\sqrt{ }$ & & $\sqrt{ }$ & & & $\sqrt{ }$ & CPLEX 12.6 & General \\
\hline Ma et al. [77] & $\begin{array}{c}\text { General } \\
\text { hierarchical }\end{array}$ & $\sqrt{ }$ & & & $\sqrt{ }$ & $\sqrt{ }$ & & & $\sqrt{ }$ & & & & Modified PSO & General \\
\hline Ng et al. [105] & Bilevel & & $\sqrt{ }$ & & & & & $\sqrt{ }$ & & & & & SA & Hurricane \\
\hline Li et al. [106] & Bilevel & & & & $\sqrt{ }$ & & & $\sqrt{ }$ & & & & $\sqrt{ }$ & L-shaped algorithm & Hurricane \\
\hline Li et al. [107] & Bilevel & & $\sqrt{ }$ & & & & $\sqrt{ }$ & $\sqrt{ }$ & & & & $\sqrt{ }$ & Lagrangian relaxation algorithm & Hurricane \\
\hline $\begin{array}{c}\text { Kongsomsaksakul et al. } \\
\text { [20] }\end{array}$ & Bilevel & & $\sqrt{ }$ & & & & & $\sqrt{ }$ & & & & & $\mathrm{GA}$ & Flood \\
\hline $\begin{array}{l}\text { Karoonsoontawong } \\
\text { and Waller [88] }\end{array}$ & Bilevel & & $\sqrt{ }$ & & & & & $\sqrt{ }$ & $\sqrt{ }$ & $\sqrt{ }$ & & & $\begin{array}{l}\text { Exact algorithm; SA, GA and } \\
\text { random search }\end{array}$ & General \\
\hline $\begin{array}{l}\text { Kulshrestha et al. [89] } \\
\text { Chen et al. [109] }\end{array}$ & $\begin{array}{l}\text { Bilevel } \\
\text { Bilevel }\end{array}$ & $\sqrt{ }$ & & & $\sqrt{ }$ & $\sqrt{ }$ & & $\sqrt{ }$ & $\begin{array}{l}\sqrt{ } \\
\sqrt{ }\end{array}$ & & $\checkmark$ & & $\begin{array}{l}\text { Cutting plane algorithm } \\
\text { LINGO } 11.0\end{array}$ & $\begin{array}{l}\text { General } \\
\text { General }\end{array}$ \\
\hline
\end{tabular}




\section{Discussion}

This review has highlighted the extensive range of disaster shelter location-allocation models that have been developed since the 1990s by surveying the site selection model types, objectives, constraints, methods for solutions, targeted disaster types, and applications. Disaster shelter location-allocation models usually have the objectives of minimizing the evacuation time or distance, shelter construction cost or number, the risk during the evacuation, along with maximizing the demand points covered within the service radius and the capacity of shelters. New objectives could be developed by integrally considering more stakeholders (e.g., shelter planners, policy makers, shelter evacuees, and non-shelter evacuees). New constraints could also be added by considering the temporal dynamics of evacuees and the ages of evacuees. Further, the capacity constraints could be soft, indicating that they could be violated due to the extreme shortage of the shelter capacity in the real situation.

To solve the disaster shelter location-allocation model, different approaches are used. Table 5 compares the different methods by pointing out their respective advantages and disadvantages. For the simple problems, such as linear integer problems, exact methods, such as enumeration, brand and bound, the cutting plane algorithm, etc., are used. For the complex problems, such as NP-hard problems, approximation algorithms, such as mathematical programming methods (e.g., Lagrangian relaxation algorithm), and heuristic algorithms (e.g., GA, PSO, SA, ACO), are used, and the latter are the most frequently used. However, no one algorithm can be seen as the best for solving the problem.

Table 5. Different methods for solving the disaster shelter location-allocation problem.

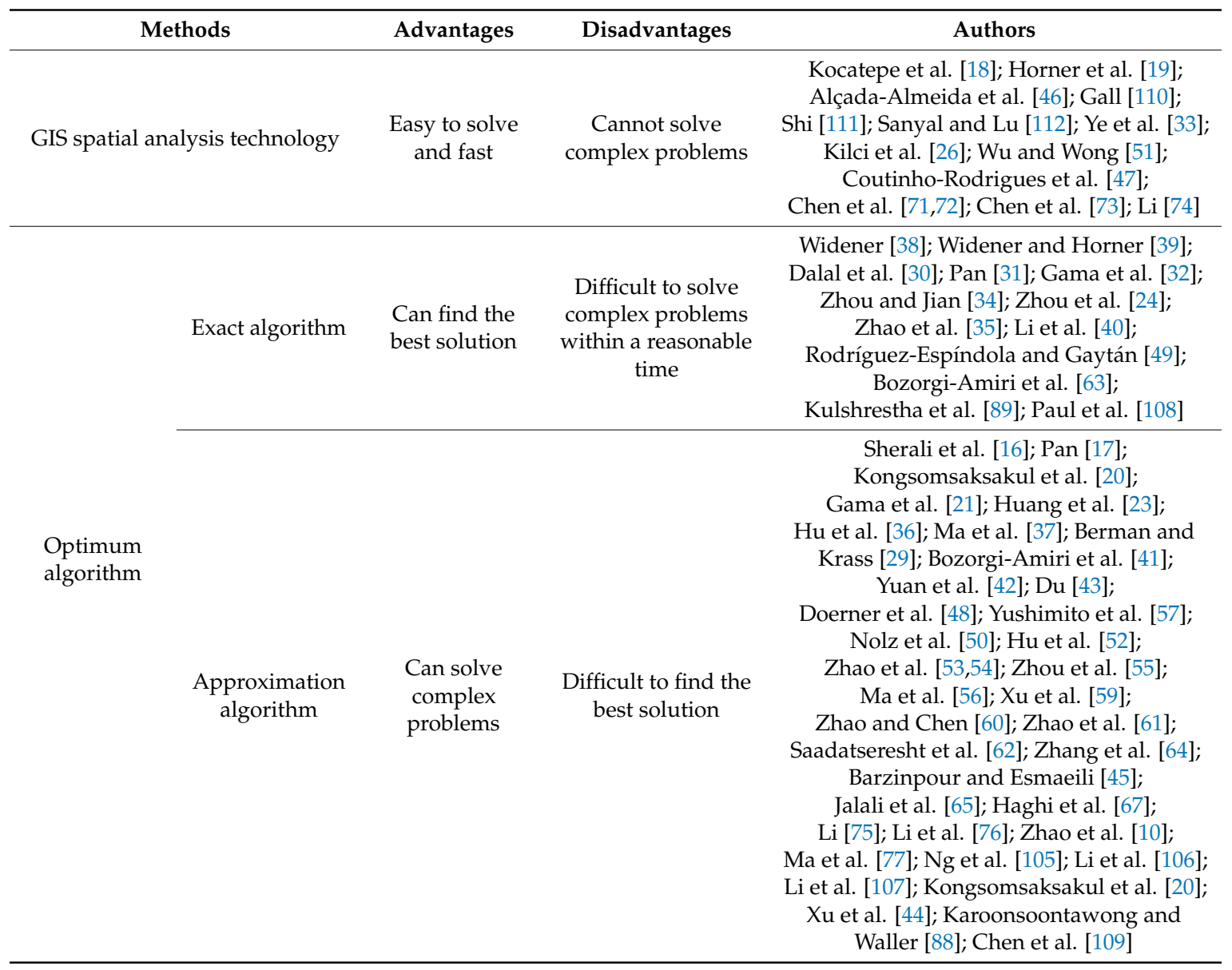


As discussed, the aspects of future development directions for the site selection model for natural disaster shelters mainly include:

The disaster characteristics should be considered when setting the models. The capacity is one of the important factors [113], as they are very important for affected people to live for a long time after the disaster. However, the evacuation paths are more important, as the evacuation time is vital for people before the arrival of the disaster. Additionally, the risk of building collapse, road damage and secondary disasters, such as slides and debris flows, should be considered when using the models. Further, different disasters have different characteristics that need to be considered when selecting the locations of shelters. Nowadays, researchers always put the focus on single disasters, which have an extreme cost of lands, especially when they are out of use. How to solve the shelter location-allocation problem by considering multiple disaster scenarios in a city, such as a city that meets with a high risk of floods and earthquakes, is another direction of study.

The designated shelter locations are fixed. However, other things, such as the number of evacuees (demand), disaster occurrence time and location (hazard), evacuation behavior (psychology), etc., are dynamic. How to consider these uncertainty factors or how to construct shelters that are not significant to these factors is another difficulty.

The existing optimization algorithms have generally been used to solve small illustrative examples of site selection problems. In the case of complex, high-dimensional problems related to large areas, the current algorithms can take an excessive amount of time and computing power and have difficulty in finding the global optimal solution [44]. Consequently, some studies continue to develop advanced algorithms [114] or divide the large-scale regions into several subregions to easily solve the above problem using current optimization software, such as LINGO or CPLEX [45]. Modifying the existing models using the dimension reduction approach is another alternative way to improve the solution quality and is one of the main directions of future research on disaster shelter location-allocation problems.

During the planning of natural disaster shelters, it is usually necessary to prioritize the designated shelters to avoid wasting resources. However, in previous research initiatives, special attention has been paid to the general location-allocation model, based on the planning of newly built shelters. Consequently, a new resource-saving supplemental location-allocation model is recognized as a major gap in scientific researches and practical applications that should be further studied going forward.

\section{Conclusions}

This paper reviewed site selection optimization models for location-allocation problems associated with natural disaster shelters, according to the type of objectives and hierarchies. Three main models were investigated: single-objective, multiobjective, and hierarchical (Figure 1). The single-objective model addressed the site selection problems for minisum problems ( $p$-median), minimax problems ( $p$-center), or covering problems, and consequently formed the basis for the multiobjective and hierarchical models. The $p$-median model and covering model are more suitable for disaster shelter site selection than the $p$-center model, so there are more relevant applications using the first two models. The multiobjective model is developed by comparing different single-objective models and combining them. However, in the case of complex, high-dimensional problems related to large areas, it can take an excessive amount of time and computing power and has difficulty finding the global optimal solution [44]. In recent years, the hierarchical models have been widely studied in many fields, and there have been a number of review papers on general hierarchical facility problems [69,70]. Among them, the bilevel model is a two-level hierarchical optimization model, where one problem is nested within another, which performs well in solving complex, high-dimensional problems. However, they are rarely involved in disaster shelter site selections, and the application researches are quite uneven among different disaster types. 

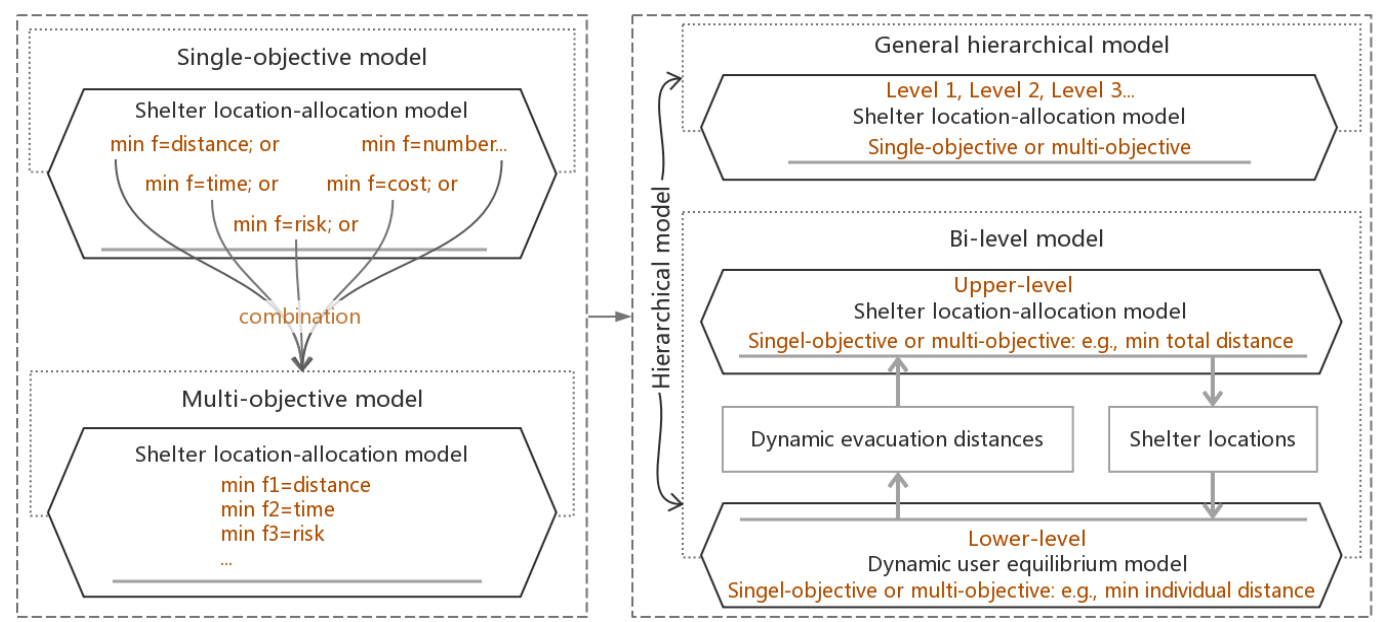

Figure 1. Three main models: single-objective, multiobjective, and hierarchical model for disaster shelter location-allocation.

Owing to the prevalence of hurricanes, floods, and earthquakes in the world, these were the main focus of natural disaster shelter location-allocation research. This review attempted to survey the site selection model types, objectives, constraints, methods for solutions, targeted disaster types and applications. The main objective of the facility location optimization model for emergency humanitarian logistics was found to be focused on responsiveness, cost-efficiency and risk [115]. Similarly, the above three are also the major criteria of natural disaster shelter site selection problems, with most models aiming to minimize the evacuation distance or time, shelter construction costs or number, transportation costs (distance or time), and risk during the evacuation, as well as maximizing the demand points covered within the service radius and the capacity of shelters. In addition, the capacity constraint and distance constraint are two widely used constraints in the shelter location-allocation problem. The exact algorithms were found to be efficiency techniques for simple problems, but approximation algorithms were found to be more effective for complex problems. Finally, research gaps and future works were identified to improve the efficiency of disaster reduction and emergency responses.

Author Contributions: W.X. designed and revised this paper; Y.M. and X.Z. collected and analyzed the literatures and wrote the paper; L.Q. provided valuable research insights into the analysis.

Funding: This study was funded by the Ministry of Science and Technology, China [2018YFC1508802, 2016YFA0602404]; National Natural Science Foundation of China [41621061, 41201547]; and Ministry of Education and State Administration of Foreign Experts Affairs, China [B08008].

Acknowledgments: Thanks to the anonymous peer reviewers and the editors for their critical comments, which helped to improve significantly the quality of this paper.

Conflicts of Interest: The authors declare no conflicts of interest.

\section{References}

1. Weber, A. Theory of the Location of Industries (1929 English Edition); The University of Chicago Press: Chicago, IL, USA, 1929.

2. Hotelling, H. Stability in competition. Econ. J. 1929, 39, 41-57. [CrossRef]

3. Smithies, A. Optimum location in spatial competition. J. Political Econ. 1941, 49, 423-439. [CrossRef]

4. Stevens, B.H. An application of game theory to a problem in location strategy. Pap. Reg. Sci. Assoc. 1961, 7, 143-157. [CrossRef]

5. Hakimi, S.L. Optimum locations of switching centers and the absolute centers and medians of a graph. Oper. Res. 1964, 12, 450-459. [CrossRef]

6. Centre for Research on the Epidemiology of Disasters (CRED). EM-DAT । The International Disasters Database. Available online: https:/ / www.emdat.be/ (accessed on 7 December 2018). 
7. Srinivas, H.; Nakagawa, Y. Environmental implications for disaster preparedness: Lessons learnt from the Indian Ocean Tsunami. J. Environ. Manag. 2008, 89, 4-13. [CrossRef]

8. Woods, C.; West, C.; Buettner, P.; Usher, K. “Out of our control”: Living through Cyclone Yasi. Int. J. Qual. Stud. Health Well-Being 2014, 9, 19821. [CrossRef]

9. Sorensen, J.H.; Shumpert, B.L.; Vogt, B.M. Planning for protective action decision making: Evacuate or shelter-in-place. J. Hazard. Mater. 2004, 109, 1-11. [CrossRef]

10. Zhao, L.; Li, H.; Sun, Y.; Huang, R.; Hu, Q.; Wang, J.; Gao, F. Planning emergency shelters for urban disaster resilience: An integrated location-allocation modeling approach. Sustainability 2017, 9, 2098. [CrossRef]

11. Dai, S.; He, L. Research on urban disaster shelter planning. J. Catastrophol. 2010, 25, 50-54. (In Chinese) [CrossRef]

12. Hakimi, S.L. Optimum distribution of switching centers in a communication network and some related graph theoretic problems. Oper. Res. 1965, 13, 462-475. [CrossRef]

13. ReVelle, C.S.; Swain, R.W. Central facilities location. Geogr. Anal. 1970, 2, 30-42. [CrossRef]

14. Mirchandani, P.B. Locational decisions on stochastic networks. Geogr. Anal. 1980, 12, 172-183. [CrossRef]

15. Larson, R.C. A hypercube queuing model for facility location and redistricting in urban emergency services. Comput. Oper. Res. 1974, 1, 67-95. [CrossRef]

16. Sherali, H.D.; Carter, T.B.; Hobeika, A.G. A location-allocation model and algorithm for evacuation planning under hurricane/flood conditions. Transp. Res. Part B Methodol. 1991, 25, 439-452. [CrossRef]

17. Pan, A. Typhoon disaster shelter selection model based on genetic algorithm. Intemet Fortune 2009, 218-219. (In Chinese)

18. Kocatepe, A.; Ozguven, E.E.; Horner, M.; Ozel, H. Pet-and special needs-friendly shelter planning in south florida: A spatial capacitated p-median-based approach. Int. J. Disaster Risk Reduct. 2018, 31, 1207-1222. [CrossRef]

19. Horner, M.W.; Ozguven, E.E.; Marcelin, J.M.; Kocatepe, A. Special needs hurricane shelters and the ageing population: Development of a methodology and a case study application. Disasters 2018, 42, 169-186. [CrossRef]

20. Kongsomsaksakul, S.; Yang, C.; Chen, A. Shelter location-allocation model for flood evacuation planning. J. East. Asia Soc. Transp. Stud. 2005, 6, 4237-4252. [CrossRef]

21. Gama, M.; Santos, B.F.; Scaparra, M.P. A multi-period shelter location-allocation model with evacuation orders for flood disasters. EURO J. Comput. Optim. 2015, 4, 1-25. [CrossRef]

22. Bayram, V.; Tansel, B.Ç.; Yaman, H. Compromising system and user interests in shelter location and evacuation planning. Transp. Res. Part B Methodol. 2015, 72, 146-163. [CrossRef]

23. Huang, H.; Lin, P.; Lo, S. The application of P-median model on emergency shelter location planning. J. Basic Sci. Eng. 2004, 12, 62-66. (In Chinese)

24. Zhou, X.; Liu, M.; Wang, Y. Emergency shelter amount confirm and location optimized. J. Saf. Environ. 2006, 6, 118-121. (In Chinese) [CrossRef]

25. Elzinga, J.; Hearn, D.W. Geometrical solutions for some minimax location problems. Transp. Sci. 1972, 6, 379-394. [CrossRef]

26. Kılc1, F.; Kara, B.Y.; Bozkaya, B. Locating temporary shelter areas after an earthquake: A case for Turkey. Eur. J. Oper. Res. 2015, 243, 323-332. [CrossRef]

27. Toregas, C.; Swain, R.; ReVelle, C.; Bergman, L. The location of emergency service facilities. Oper. Res. 1971, 19, 1363-1373. [CrossRef]

28. Church, R.; Velle, C.R. The maximal covering location problem. Pap. Reg. Sci. Assoc. 1974, 32, $101-118$. [CrossRef]

29. Berman, O.; Krass, D. The generalized maximal covering location problem. Comput. Oper. Res. 2002, 29, 563-581. [CrossRef]

30. Dalal, J.; Mohapatra, P.K.; Mitra, G.C. Locating cyclone shelters: A case. Disaster Prev. Manag. 2007, 16, 235-244. [CrossRef]

31. Pan, A. The applications of maximal covering model in typhoon emergency shelter location problem. In Proceedings of the IEEE Industrial Engineering and Engineering Management (IEEM), Macao, China, 7-10 December 2010; pp. 1727-1731. [CrossRef] 
32. Gama, M.; Scaparra, M.P.; Santos, B.F. Optimal Location of Shelters for Mitigating Urban Floods. In Proceedings of the EWGT 2013-16th Meeting of the EURO Working Group on Transportation, Porto, Portugal, 4-6 September 2013.

33. Ye, M.; Wang, J.; Huang, J.; Xu, S.; Chen, Z. Methodology and its application for community-scale evacuation planning against earthquake disaster. Nat. Hazards 2012, 61, 881-892. [CrossRef]

34. Zhou, T.; Jian, F. Study on establishing the supporting system for location of the urgent refuge. Res. Soil Water Conserv. 2001, 8, 17-24. (In Chinese) [CrossRef]

35. Zhao, L.; Wang, K.; Wang, J. Theory and Method for Unban Emergency Shelter Planning; Science Press: Beijing, China, 2014; p. 143. (In Chinese)

36. Hu, F.; Xu, W.; Li, X. A modified particle swarm optimization algorithm for optimal allocation of earthquake emergency shelters. Int. J. Geogr. Inf. Sci. 2012, 26, 1643-1666. [CrossRef]

37. Ma, Y.; Zhao, X.; Qin, L.; Liang, P.; Zhou, H.; Yuan, Y.; Xu, W. A comparison of single-objective and bi-level location-allocation model for earthquake emergency shelters with the case of Rongcheng in Shandong. J. Catastrophol. 2017, 32, 189-194. (In Chinese) [CrossRef]

38. Widener, M.J.; Horner, M.W. Modeling Hurricane Disaster Relief Distribution with a Hierarchical Capacitated-Median Model. Master's Thesis, Florida State University, Tallahassee, FL, USA, 2009.

39. Widener, M.J.; Horner, M.W. A hierarchical approach to modeling hurricane disaster relief goods distribution. J. Transp. Geogr. 2011, 19, 821-828. [CrossRef]

40. Li, G.C. TISEM: A two-stage interval-stochastic evacuation management model. J. Environ. Inform. 2008, 12, 64-74. [CrossRef]

41. Bozorgi-Amiri, A.; Jabalameli, M.S.; Alinaghian, M.; Heydari, M. A modified particle swarm optimization for disaster relief logistics under uncertain environment. Int. J. Adv. Manuf. Technol. 2012, 60, 357-371. [CrossRef]

42. Yuan, Y.; Liu, Y.; Zhu, S.; Wang, J. Maximal preparedness coverage model and its algorithm for emergency shelter location. J. Nat. Disasters 2015, 24, 8-14. (In Chinese) [CrossRef]

43. Du, S. Urban Emergency Shelter Site Selection Method Based on Ant Colony Algorithm; Shanghai Normal University: Shanghai, China, 2018. (In Chinese)

44. Xu, W.; Ma, Y.; Zhao, X.; Li, Y.; Qin, L.; Du, J. A comparison of scenario-based hybrid bilevel and multi-objective location-allocation models for earthquake emergency shelters: A case study in the central area of Beijing, China. Int. J. Geogr. Inf. Sci. 2018, 32, 236-256. [CrossRef]

45. Barzinpour, F.; Esmaeili, V. A multi-objective relief chain location distribution model for urban disaster management. Int. J. Adv. Manuf. Technol. 2014, 70, 1291-1302. [CrossRef]

46. Alçada Almeida, L.; Tralhao, L.; Santos, L.; Coutinho Rodrigues, J. A multiobjective approach to locate emergency shelters and identify evacuation routes in urban areas. Geogr. Anal. 2009, 41, 9-29. [CrossRef]

47. Coutinho-Rodrigues, J.; Tralhão, L.; Alçada-Almeida, L. Solving a location-routing problem with a multiobjective approach: The design of urban evacuation plans. J. Transp. Geogr. 2012, 22, 206-218. [CrossRef]

48. Doerner, K.F.; Gutjahr, W.J.; Nolz, P.C. Multi-criteria location planning for public facilities in tsunami-prone coastal areas. OR Spectr. 2009, 31, 651-678. [CrossRef]

49. Rodríguez-Espíndola, O.; Gaytán, J. Scenario-based preparedness plan for floods. Nat. Hazards 2015, 76, 1241-1262. [CrossRef]

50. Nolz, P.C.; Semet, F.; Doerner, K.F. Risk approaches for delivering disaster relief supplies. OR Spectr. 2011, 33, 543-569. [CrossRef]

51. Wu, J.; Wong, W. Decision support system for urban shelter locations. J. Tsinghua Univ. 2011, 51, $632-636$. (In Chinese) [CrossRef]

52. Hu, F.; Yang, S.; Xu, W. A non-dominated sorting genetic algorithm for the location and districting planning of earthquake shelters. Int. J. Geogr. Inf. Sci. 2014, 28, 1482-1501. [CrossRef]

53. Zhao, X.; Xu, W.; Ma, Y.; Hu, F. Scenario-based multi-objective optimum allocation model for earthquake emergency shelters using a modified particle swarm optimization algorithm: A case study in Chaoyang district, Beijing, China. PLoS ONE 2015, 10, e144455. [CrossRef]

54. Zhao, X.; Xu, W.; Ma, Y.; Qin, L.; Zhang, J.; Wang, Y. Relationships between evacuation population size, earthquake emergency shelter capacity, and evacuation time. Int. J. Disaster Risk Sci. 2017, 8, 457-470. [CrossRef] 
55. Zhou, Y.; Liu, M.; Wang, L. Study of urban shelter location planning based on multi-objective approach. J. Saf. Environ. 2010, 10, 205-209. (In Chinese) [CrossRef]

56. Ma, Y.; Zhao, X.; Qin, L.; Liang, P.; Zhou, H.; Yuan, Y.; Xu, W. Multi-objective Location-allocation Model for Earthquake Emergency Shelters with Multiple Constraints: A Case Study in Wenchang of Hainan Province. J. Catastrophol. 2018, 33, 218-224. (In Chinese) [CrossRef]

57. Yushimito, W.F.; Jaller, M.; Ukkusuri, S. A Voronoi-based heuristic algorithm for locating distribution centers in disasters. Netw. Spat. Econ. 2012, 12, 21-39. [CrossRef]

58. Tzeng, G.; Cheng, H.; Huang, T.D. Multi-objective optimal planning for designing relief delivery systems. Transp. Res. Part E Logist. Transp. Rev. 2007, 43, 673-686. [CrossRef]

59. Xu, W.; Zhao, X.; Ma, Y.; Li, Y.; Qin, L.; Wang, Y.; Du, J. A multi-objective optimization based method for evaluating earthquake shelter location-allocation. Geomat. Nat. Hazards Risk 2018, 9, 662-677. [CrossRef]

60. Zhao, M.; Chen, Q. Risk-based optimization of emergency rescue facilities locations for large-scale environmental accidents to improve urban public safety. Nat. Hazards 2015, 75, 163-189. [CrossRef]

61. Zhao, M.; Chen, Q.W.; Ma, J.; Cai, D. Optimizing temporary rescue facility locations for large-scale urban environmental emergencies to improve public safety. J. Environ. Inform. 2017, 29, 61-73. [CrossRef]

62. Saadatseresht, M.; Mansourian, A.; Taleai, M. Evacuation planning using multiobjective evolutionary optimization approach. Eur. J. Oper. Res. 2009, 198, 305-314. [CrossRef]

63. Bozorgi-Amiri, A.; Jabalameli, M.S.; Al-e-Hashem, S.M. A multi-objective robust stochastic programming model for disaster relief logistics under uncertainty. OR Spectr. 2013, 35, 905-933. [CrossRef]

64. Zhang, J.; Dong, M.; Chen, F.F. A bottleneck Steiner tree based multi-objective location model and intelligent optimization of emergency logistics systems. Robot. Comput.-Integr. Manuf. 2013, 29, 48-55. [CrossRef]

65. Jalali, S.; Seifbarghy, M.; Sadeghi, J.; Ahmadi, S. Optimizing a bi-objective reliable facility location problem with adapted stochastic measures using tuned-parameter multi-objective algorithms. Knowl.-Based Syst. 2016, 95, 45-57. [CrossRef]

66. Trivedi, A.; Singh, A. A hybrid multi-objective decision model for emergency shelter location-relocation projects using fuzzy analytic hierarchy process and goal programming approach. Int. J. Proj. Manag. 2017, 35, 827-840. [CrossRef]

67. Haghi, M.; Ghomi, S.M.T.F.; Jolai, F. Developing a robust multi-objective model for pre/post disaster times under uncertainty in demand and resource. J. Clean. Prod. 2017, 154, 188-202. [CrossRef]

68. Narula, S.C.; Ogbu, U.I. An hierarchal location-allocation problem. Omega 1979, 7, 137-143. [CrossRef]

69. Şahin, G.; Süral, H. A review of hierarchical facility location models. Comput. Oper. Res. 2007, 34, $2310-2331$. [CrossRef]

70. Farahani, R.Z.; Hekmatfar, M.; Fahimnia, B.; Kazemzadeh, N. Survey: Hierarchical facility location problem: Models, classifications, techniques, and applications. Comput. Ind. Eng. 2014, 68, 104-117. [CrossRef]

71. Chen, Z.; Gu, L.; Chen, J.; Li, Q. Study on hierarchical location of urban emergency shelters (I)-hierarchy analysis. J. Nat. Disasters 2010, 19, 151-155. (In Chinese) [CrossRef]

72. Chen, Z.; Li, Q.; Chen, J. Study on hierarchical location of urban emergency shelters (II)-three-hierarchical location models. J. Nat. Disasters 2010, 19, 13-19. (In Chinese) [CrossRef]

73. Chen, Z.; Chen, X.; Li, Q.; Chen, J. The temporal hierarchy of shelters: A hierarchical location model for earthquake-shelter planning. Int. J. Geogr. Inf. Sci. 2013, 27, 1612-1630. [CrossRef]

74. Li, Y. Study on the location selection and spatial layout of urban shelters against the earthquake disaster-A case study in Zhangqiu city. Master's Thesis, Shandong Jianzhu University, Jinan, China, 2014. (In Chinese)

75. Li, H.; Zhaong, Y.; Gao, P. Hierarchical location selection and layout optimization of emergency shelter system in satellite town-A case of Yanjiao Town in Hebei Province. Sci. Technol. Eng. 2017, 17, 96-104. (In Chinese)

76. Li, H.; Zhao, L.; Huang, R.; Hu, Q. Hierarchical earthquake shelter planning in urban areas: A case for Shanghai in China. Int. J. Disaster Risk Reduct. 2017, 22, 431-446. [CrossRef]

77. Ma, Y.; Xu, W.; Qin, L.; Zhao, X.; Du, J. Hierarchical supplement location-allocation optimization for disaster supplies warehouse in the Beijing-Tianjin-Hebei region of China. Geomat. Nat. Hazards Risk 2018. [CrossRef]

78. Du, J.; Li, X.; Yu, L.; Dan, R.; Zhou, J. Multi-depot vehicle routing problem for hazardous materials transportation: A fuzzy bilevel programming. Inf. Sci. 2017, 399, 201-218. [CrossRef]

79. Von Stackelberg, H. Marktform und Gleichgewicht; Springer: Berlin, Germany, 1934. 
80. Dempe, S. Annotated bibliography on bilevel programming and mathematical programs with equilibrium constraints. Optimization 2003, 52, 333-359. [CrossRef]

81. Migdalas, A.; Pardalos, P.M.; Värbrand, P. Multilevel Optimization: Algorithms and Applications; Kluwer Academic Publishers: Dordrechts, The Netherlands, 1998.

82. Dempe, S. Foundations of Bilevel Programming; Kluwer Academic Publishers: Dordrecht, The Netherlands, 2002.

83. Bracken, J.; McGill, J.T. Mathematical programs with optimization problems in the constraints. Oper. Res. 1973, 21, 37-44. [CrossRef]

84. Bracken, J.; McGill, J.T. Defense applications of mathematical programs with optimization problems in the constraints. Oper. Res. 1974, 22, 1086-1096. [CrossRef]

85. Fisk, C.S. Game theory and transportation systems modelling. Transp. Res. Part B Methodol. 1984, 18, 301-313. [CrossRef]

86. Dow, K.; Cutter, S.L. Emerging hurricane evacuation issues: Hurricane Floyd and South Carolina. Nat. Hazards Rev. 2002, 3, 12-18. [CrossRef]

87. Chiu, Y.; Korada, P.; Mirchandani, P.B. Dynamic traffic management for evacuation. In Proceedings of the 84th Annual Meeting of the Transportation Research Board (CD-ROM), Washington, DC, USA, 9-13 January 2005.

88. Karoonsoontawong, A.; Waller, S.T. Dynamic continuous network design problem: Linear bilevel programming and metaheuristic approaches. Transp. Res. Rec. J. Transp. Res. Board 2006, 1964, 104-117. [CrossRef]

89. Kulshrestha, A.; Wu, D.; Lou, Y.; Yin, Y. Robust shelter locations for evacuation planning with demand uncertainty. J. Transp. Saf. Secur. 2011, 3, 272-288. [CrossRef]

90. Calvete, H.I.; Galé, C. Linear bilevel programs with multiple objectives at the upper level. J. Comput. Appl. Math. 2010, 234, 950-959. [CrossRef]

91. Yin, Y. Multiobjective bilevel optimization for transportation planning and management problems. J. Adv. Transp. 2002, 36, 93-105. [CrossRef]

92. Sinha, A.; Malo, P.; Frantsev, A.; Deb, K. Multi-objective stackelberg game between a regulating authority and a mining company: A case study in environmental economics. In Proceedings of the IEEE Congress on Evolutionary Computation (CEC), Cancun, Mexico, 20-23 June 2013; pp. 478-485. [CrossRef]

93. Ankhili, Z.; Mansouri, A. An exact penalty on bilevel programs with linear vector optimization lower level. Eur. J. Oper. Res. 2009, 197, 36-41. [CrossRef]

94. Calvete, H.I.; Galé, C. On linear bilevel problems with multiple objectives at the lower level. Omega 2011, 39, 33-40. [CrossRef]

95. Limleamthong, P.; Guillén-Gosálbez, G. Rigorous analysis of Pareto fronts in sustainability studies based on bilevel optimization: Application to the redesign of the UK electricity mix. J. Clean. Prod. 2017, 164, 1602-1613. [CrossRef]

96. Bonnel, H.; Morgan, J. Optimality conditions for semivectorial bilevel convex optimal control problems. In Computational and Analytical Mathematics; Springer: Berlin, Germany, 2013; pp. 45-78. [CrossRef]

97. Halter, W.; Mostaghim, S. Bilevel optimization of multi-component chemical systems using particle swarm optimization. In Proceedings of the IEEE International Conference on Evolutionary Computation (CEC), Vancouver, BC, Canada, 16-21 July 2006; pp. 1240-1247. [CrossRef]

98. Deb, K.; Sinha, A. An efficient and accurate solution methodology for bilevel multi-objective programming problems using a hybrid evolutionary-local-search algorithm. Evol. Comput. 2010, 18, 403-449. [CrossRef] [PubMed]

99. Sinha, A.; Malo, P.; Deb, K.; Korhonen, P.; Wallenius, J. Solving bilevel multicriterion optimization problems with lower level decision uncertainty. IEEE Trans. Evol. Comput. 2016, 20, 199-217. [CrossRef]

100. Zhang, T.; Hu, T.; Zheng, Y.; Guo, X. An improved particle swarm optimization for solving bilevel multiobjective programming problem. J. Appl. Math. 2012, 2012, 359-373. [CrossRef]

101. Eichfelder, G. Multiobjective bilevel optimization. Math. Program. 2010, 123, 419-449. [CrossRef]

102. Shi, X.; Xia, H. Interactive bilevel multi-objective decision making. J. Oper. Res. Soc. 1997, 48, 943-949. [CrossRef]

103. Shi, X.; Xia, H.S. Model and interactive algorithm of bi-level multi-objective decision-making with multiple interconnected decision makers. J. Multi-Criteria Decis. Anal. 2001, 10, 27-34. [CrossRef] 
104. Sinha, A.; Malo, P.; Deb, K. Transportation policy formulation as a multi-objective bilevel optimization problem. In Proceedings of the IEEE Congress on Evolutionary Computation (CEC), Sendai, Japan, 25-28 May 2015; pp. 1651-1658. [CrossRef]

105. Ng, M.W.; Park, J.; Waller, S.T. A Hybrid Bilevel Model for the Optimal Shelter Assignment in Emergency Evacuations. Comput.-Aided Civ. Infrastruct. Eng. 2010, 25, 547-556. [CrossRef]

106. Li, L.; Jin, M.; Zhang, L. Sheltering network planning and management with a case in the Gulf Coast region. Int. J. Prod. Econ. 2011, 131, 431-440. [CrossRef]

107. Li, A.C.Y.; Nozick, L.; Xu, N.; Davidson, R. Shelter location and transportation planning under hurricane conditions. Transp. Res. Part E Logist. Transp. Rev. 2012, 48, 715-729. [CrossRef]

108. Paul, N.R.; Lunday, B.J.; Nurre, S.G. A multiobjective, maximal conditional covering location problem applied to the relocation of hierarchical emergency response facilities. Omega 2017, 66, 147-158. [CrossRef]

109. Chen, H.; Chu, J.; Ma, D.; Sun, T. Location Selection of Emergency Shelter Optimization Model for Disaster Prevention. J. North China Univ. Sci. Technol. 2016, 38, 149-156. (In Chinese) [CrossRef]

110. Gall, M. Where to go? Strategic modelling of access to emergency shelters in Mozambique. Disasters 2004, 28, 82-97. [CrossRef] [PubMed]

111. Shi, X. Evaluate the efficacy and optimize addressing option on urban disaster-prevention space. Master's Thesis, Xi'an University of Architecture and Technology, Xi'an, China, 2006. (In Chinese)

112. Sanyal, J.; Lu, X.X. Ideal location for flood shelter: A geographic information system approach. J. Flood Risk Manag. 2009, 2, 262-271. [CrossRef]

113. Xu, W.; Li, Y.; Okada, N.; Takeuchi, Y.; Kajitani, Y.; Shi, P. Collaborative modelling-based shelter planning analysis: A case study of the Nagata Elementary School Community in Kobe City, Japan. Disasters 2014, 38, 125-147. [CrossRef] [PubMed]

114. Zheng, Y.; Chen, S.; Ling, H. Evolutionary optimization for disaster relief operations. Appl. Soft Comput. 2015, 27, 553-566. [CrossRef]

115. Boonmee, C.; Arimura, M.; Asada, T. Facility location optimization model for emergency humanitarian logistics. Int. J. Disaster Risk Reduct. 2017, 24, 485-498. [CrossRef]

(C) 2019 by the authors. Licensee MDPI, Basel, Switzerland. This article is an open access article distributed under the terms and conditions of the Creative Commons Attribution (CC BY) license (http://creativecommons.org/licenses/by/4.0/). 